\title{
Generating a High Valency Biotin Binder by Selecting Uniform Protein Assemblies via Crystallization
}

\author{
Orly Avraham ${ }^{1}$, Yael Levi-Kalisman ${ }^{2}$ and Oded Livnah ${ }^{1, *(1)}$ \\ 1 Department of Biological Chemistry, The Alexander Silverman Institute of Life Sciences, The Wolfson Centre \\ for Applied Structural Biology, The Hebrew University of Jerusalem, The Edmond J. Safra Campus, \\ Jerusalem 91904, Israel \\ 2 Center for Nanoscience and Nanotechnology, and The Alexander Silverman Institute of Life Sciences, \\ The Hebrew University of Jerusalem, The Edmond J. Safra Campus, Jerusalem 91904, Israel \\ * Correspondence: oded.livnah@huji.ac.il; Tel.: +972-2-658-6894
}

Received: 28 May 2019; Accepted: 9 July 2019; Published: 11 July 2019

check for updates

\begin{abstract}
Crystallization is a common practice in the purification process in small molecule synthesis while selecting the wanted product. For proteins it is rarely applied due to the methodological predicaments in obtaining crystals. Our observation of the stabilized octamers in the crystal structure of hoefavidin, a novel dimeric member of the avidin family, led to the notion of developing a novel biotechnological tool via covalent crosslinking. The avidin-biotin system has been exploited for decades utilizing the ultra-high affinity between avidin and biotin as a basis for numerous applications. Optimizing the system led to the discovery of a novel group of dimeric avidins including hoefavidin. Hoefavidin has a dynamic quaternary structure, where a dimer is the basis for generating the octamer via crystallographic symmetry operation. Upon biotin binding in solution hoefavidin dissociates solely into dimers. In order to stabilize the octamer, we designed the P61C mutant to form a disulfide bridge stabilizing the octamer and preventing dissociation upon biotin binding. The process of selecting P61C hoefavidin uniform octamers includes crystallization followed by dissolving the crystals. The P61C modified hoefavidin octamer can have a substantial added value to the various biotechnological applications and advances of the biotin based high affinity systems.
\end{abstract}

Keywords: protein crystallography; crystal packing; avidin; biotin; nanotechnology

\section{Introduction}

The biotin based high affinity systems are regularly used in many and diverse applications [1-3]. This system is useful due to the uniquely extreme high affinity between the hen egg white avidin, and its ligand biotin, with a $\mathrm{Kd}$ of approximately $10^{-15} \mathrm{M}[4,5]$. The avidin family contains many proteins with new members regularly discovered, including the abundantly used streptavidin from Streptomyces avidinii [6]. Other members include proteins from different organisms, such as fungi, xenopus, avians, zebrafish, bacteria and others [7-12]. These avidins assemble into homotetramers with four biotin binding sites, one per monomer (Figure 1) [13-15]. The monomers have a conserved topology consisting of an eight stranded $\beta$-barrel, with the biotin binding site at the wide end of the barrel (Figure 1). The tetrameric avidins have three types of monomer-monomer interactions, as described by Livnah et al. [15]. Briefly, the 1-2 interaction contains an essential Trp residue that is critical for the high affinity towards biotin and the tetrameric stability. The 1-3 interaction is small with only a few participating amino acids. The 1-4 interaction is the largest, with more than $1200 \AA^{2}$ per monomer and is pivotal for the stability of the tetrameric assembly and termed the sandwich-like dimer [16]. 
Although utilized in many biotechnological and biomedical applications, many studies are still conducted in an effort to alter and optimize the avidin biotin system in order to diversify its usage [17-22]. The tetrameric assembly could be regarded as a drawback in several cases when quantification is required, since the precise occupancy cannot be assessed, and applications based on fusion proteins are less suitable due to the presence of four identical monomers. In addition to the attempts to minimize avidins, it could also be beneficial to design or form avidin assemblies with more biotin binding sites where biotin-conjugated markers could be enhanced. Higher valency avidins would have a different spatial arrangement than the standard tetramer, which would also contribute to diverseness of the avidin-biotin system. Additionally, using an octameric biotin binder with more biotin binding sites, compared to avidin, will reduce the amount of molecules used, thus enabling higher protein content while reducing the solvent for the hydration shell [23].
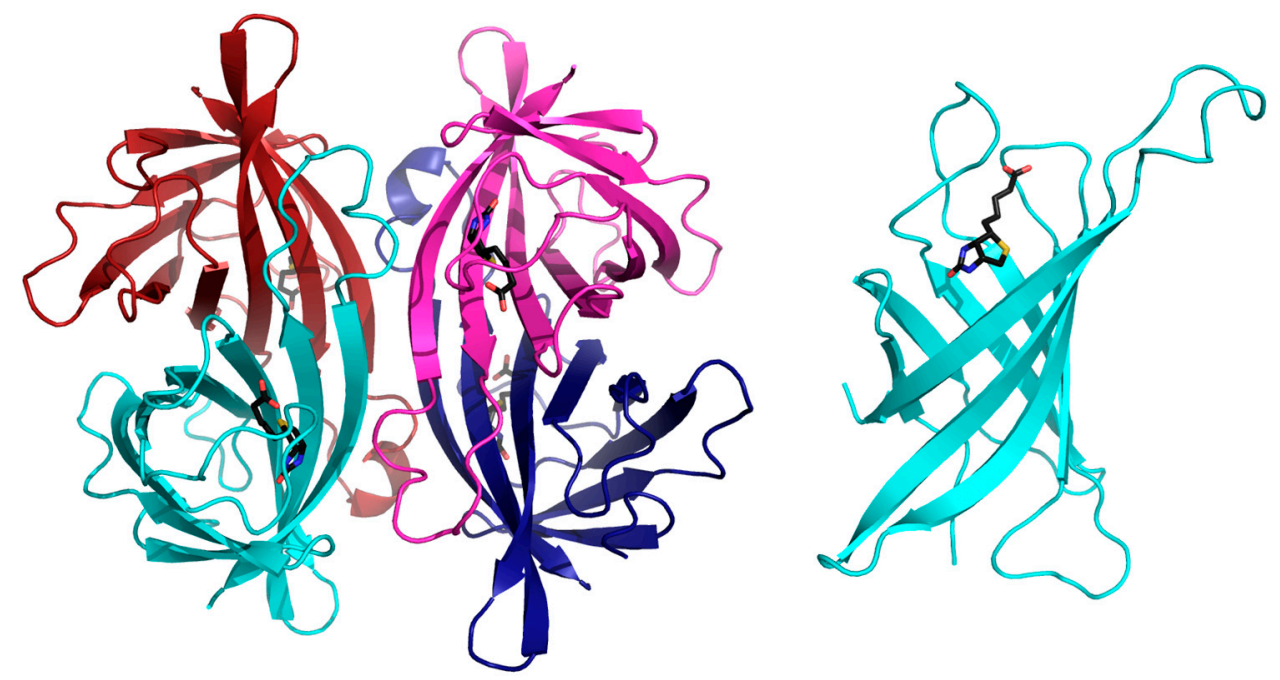

Figure 1. Three-dimensional structure of avidin, as a representative of the tetrameric avidins. The left image displays a cartoon representation of the tetrameric assembly of avidins where each monomer is depicted in magenta, blue, cyan and red. Each monomer has a single biotin (shown in black) binding site. The right image shows the avidin monomer consisting of an 8-anti parallel stranded $\beta$-barrel topology with the biotin molecule (shown in black) at the wide end of the barrel (monomer size not to scale compared to the tetramer).

Solutions to challenges and biotechnological development were regularly pursued where novel family members that have smaller valency were found, compiling a new sub-family-the dimeric avidins [16,24-27]. These contain a highly similar fold of the canonical monomers that form the 1-4 dimer. The crystal structures of the dimeric avidins have been previously determined and displayed a higher oligomeric assembly in the crystalline states of the apo forms [16,24-26,28]. In this regard, rhizavidin and shwanavidin form cylindrical hexamers, while hoefavidin and afifavidin form cylindrical octamers, generated using crystallographic symmetry operations. These oligomeric assemblies, regarded initially as crystallization flukes, were recently shown for hoefavidin and afifavidin to be also present in solution [26]. These unique assemblies introduce a novel arrangement for biotin binding proteins with three or four biotin binding sites on each side of the oligomers, resulting in a total of six or eight possible biotin molecules per protein. Upon biotin binding the octamers were shown to disassemble in solution into dimers [26], thus presenting a potential advantage for utilizing these proteins and their increased valency.

In this study, we have designed a covalently linked molecule based on the hoefavidin octameric assembly observed in the crystalline state (Figure 2), with eight biotin binding sites, that is stable in solution even upon biotin binding and could be utilized in novel applications. In this context, we have stabilized hoefavidin using a single point mutation $\mathrm{P} \rightarrow \mathrm{C}$ promoting the formation of a disulfide bond 
in the interface between monomers. The crystal structure of the covalently stabilized octamer has the same topology as the wild-type (wt) apo hoefavidin (PDB code 4Z6J) [24], with four biotin binding sites on each side with a total of eight binding sites. Due to this covalently linked octameric assembly, it does not dissociate into dimers upon biotin binding, thus allowing the employment of an additional tool in biotechnological applications and enabling a signal stronger by two-fold in comparison to avidin and streptavidin.

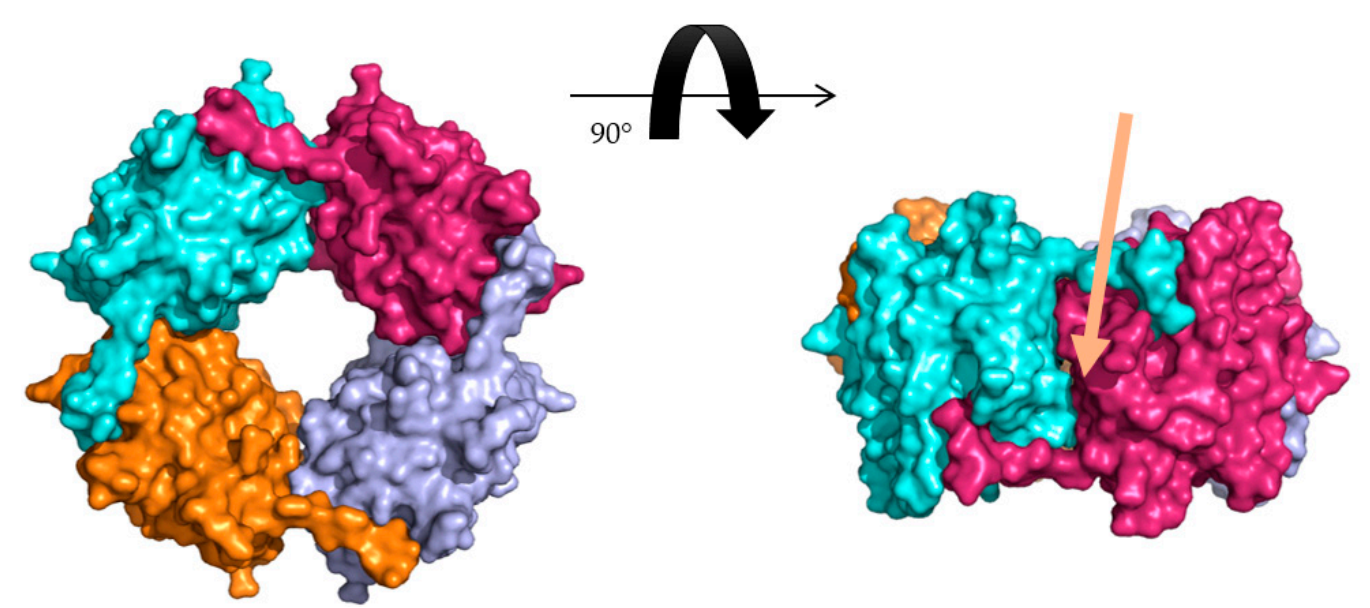

Figure 2. Octameric assembly of hoefavidin. Surface representation of the octameric assembly of wild type apo hoefavidin (PDB code 4Z6J) as observed in the crystalline state where each of the dimers are shown in cyan, purple, light blue and orange. The C-terminal segment of each monomer penetrates to the biotin binding site of its adjacent non-canonical dimer contributing to the stability of the assembly. The right panel is rotated by $90^{\circ}$ along the horizontal axis exemplifying the non-canonical interface and the role of the c-term region, with the interface indicated by the arrow.

\section{Materials and Methods}

\subsection{Identification, Expression and Purification of P61C Hoefavidin}

The P61C hoefavidin construct was designed based on the solved three-dimensional structure of intact hoefavidin (PDB ID: 4Z6J). Mutation was performed using PCR and cloned into pET28a plasmid (Novagen). Octameric hoefavidin was expressed in E. coli strain BL21 DE3 pLysS (Invitrogen). Cells were cultured in 2xYT medium supplemented with $100 \mu \mathrm{g} / \mathrm{mL}$ kanamycin (Biological industries) at $37^{\circ} \mathrm{C}$, with rotation $(220 \mathrm{rpm})$. When $\mathrm{OD}_{\lambda}=600 \mathrm{~nm}$ reached a value of $0.5-0.7,0.4 \mathrm{mM}$ isopropyl 1-thio- $\beta$-D-galactopyranoside (IPTG) was added for induction. Cultivation was continued for $5 \mathrm{~h}$ at $30{ }^{\circ} \mathrm{C}$ in a shaker incubator with rotations of $220 \mathrm{rpm}$. After induction by IPTG and growth, cells were harvested and resuspended in 1:10 lysis buffer containing $0.3 \mathrm{M} \mathrm{NaCl}, 50 \mathrm{mM}$ Tris $\mathrm{HCl} \mathrm{pH}$ 8.0, $1 \mathrm{mM}$ GSH, $0.1 \mathrm{mM}$ GSSG and 0.5 M Guanidine $\mathrm{HCl}$, lysis buffer to initial bacterial amount. In addition, protease inhibitor cocktail (Sigma-Aldrich) was added at a ratio of 1:400 to the buffer, lysozyme was added at a ratio of $2.5 \mathrm{mg}$ per liter of bacteria and DNase was added at a ratio of $1 \mathrm{mg}$ per liter bacteria, with $20 \mathrm{mM} \mathrm{MgCl}_{2}$. Resuspension and $20 \mathrm{~min}$ of additional incubation were conducted on ice. Lysis was performed using a microfluidizer at 20,000 psi (LV1, Microfluidics). The lysate was then centrifuged at $16,500 \mathrm{~g}$ for $25 \mathrm{~min}$ at $4{ }^{\circ} \mathrm{C}$, and the supernatant was separated.

Preliminary verification of correct folding of the P61C hoefavidin was conducted by a binding assay to biotin-4-fluorescein (B4F). For this purpose, $15 \mu \mathrm{L}$ of crude supernatant fluids were incubated with $0.6 \mathrm{mM} \mathrm{B} 4 \mathrm{~F}$ for $30 \mathrm{~min}$ at room temperature and then separated and analyzed on a native acryl amide gel [29,30]. The supernatant was then diluted at a 1:1 ratio using a binding buffer [31], containing $1 \mathrm{M} \mathrm{NaCl}$ and $50 \mathrm{mM} \mathrm{Na} 2 \mathrm{CO} 3$ at $\mathrm{pH} 11$, and was titrated to the $\mathrm{pH}$ value of 11.0 using $\mathrm{NaOH}$. The diluted supernatant solution was then incubated for $10 \mathrm{~min}$ at $4{ }^{\circ} \mathrm{C}$ with 2-iminobiotin resin (PIERCE). Following protein binding at high $\mathrm{pH}$, the beads were spun down gently (500 RPM, $3 \mathrm{~min}$ ) and the 
unbound fraction was removed. The protein was eluted by transferring the beads and the bound P61C hoefavidin to a gravity column and then using a low $\mathrm{pH}$ buffer (0.1 M acetic acid, $\mathrm{pH}$ 3.0) [31]. Protein purity was evaluated via SDS-PAGE and concentrated to a final concentration of $5 \mathrm{mg} / \mathrm{mL}$ using a $2 \mathrm{~mL}$ Centricon with $5000 \mathrm{MWCO}$ (Biological industries) and consequently stored at $-80^{\circ} \mathrm{C}$.

\subsection{Crystallization, Data Collection and Structure Solution}

Crystals of the apo P61C hoefavidin were obtained via vapor diffusion sitting drop setup, using similar conditions to those of the wt intact hoefavidin, by cross streak seeding from the wt intact hoefavidin [32,33]. All indications in text of apo P61C hoefavidin hereafter are termed P61C hoefavidin unless stated otherwise. Crystals appeared within several days in a condition containing $2 \mu \mathrm{L}$ of equal amounts of $3.4 \mathrm{mg} / \mathrm{mL}$ protein mixed with $1.3 \mathrm{M} \mathrm{Li}_{2} \mathrm{SO}_{4}$ and $0.1 \mathrm{M}$ HEPES $\mathrm{pH} 7.5$ reaching the average size of $0.15 \times 0.15 \times 0.15 \mathrm{~mm}$. For data collection, crystals were briefly suspended in a cryoprotectant solution containing $25 \%$ glycerol and the crystallization solution. Data were collected at the European Synchrotron Radiation Facility (ESRF), Grenoble, France, at $100 \mathrm{~K}$, using an Oxford Cryosystems Cryostream cooling device. All data were processed and scaled using the XDS via EDNA [34]. Crystals of the P61C hoefavidin diffracted to the highest resolution of $2.0 \AA$ and belong to the $\mathrm{P}_{2} 22$ hexagonal space group with 2 monomers in the asymmetric unit (Table 1). The structure of P61C hoefavidin was solved by molecular replacement using MolRep, implemented in the CCP4 suite [35,36]. The search model was the intact hoefavidin structure [24]. The structure of the P61C hoefavidin was initially refined using the restrained refinement mode in Refmac [36,37]. The structure was further refined at a resolution range of 43.48.0-2.0 $\AA$, and solvent molecules were added with Coot [38] resulting in the final R-value of $22.7 \%$ and R-free of $28.3 \%$. (Table 1 ).

Table 1. Data collection and refinement statistics.

\begin{tabular}{|c|c|}
\hline PDB Entry & 6RTQ \\
\hline ESRF Beamline & D23-1 \\
\hline Wavelength $(\AA)$ & 0.978 \\
\hline Space Group & $\mathrm{P} 6_{2} 22$ \\
\hline Unit Cell Parameters $(\AA)$ & $a=81.4, c=130.4$ \\
\hline Resolution Range (Å) & $43.48-2.00$ \\
\hline (Outer shell) & $(2.05-2.00)$ \\
\hline Mosaicity $\left({ }^{\circ}\right)$ & 0.23 \\
\hline Unique Reflections & $18,089(1313)$ \\
\hline Redundancy & 6.1 \\
\hline $\operatorname{Rsym}(\mathrm{I})^{a}$ & $4.0(78.4)$ \\
\hline Rmeas & $4.4(89.6)$ \\
\hline Rpim & $2.4(61.9)$ \\
\hline Completeness & $99.7(99.1)$ \\
\hline $\mathrm{I} / \sigma$ & $17.8(1.6)$ \\
\hline CC $(1 / 2)$ & $99.9(62.8)$ \\
\hline Number of protein atoms & 1996 \\
\hline Number of solvent atoms & 77 \\
\hline R-factor & $22.7(39.4)$ \\
\hline R-free ${ }^{b}$ & $28.3(38.0)$ \\
\hline \multicolumn{2}{|c|}{ Average B factor $\left(\AA^{2}\right)$} \\
\hline Protein & 62.2 \\
\hline Solvent & 59.7 \\
\hline \multicolumn{2}{|c|}{ rmsd from ideality } \\
\hline Bond Length & 0.014 \\
\hline Bond Angle & 2.1 \\
\hline \multicolumn{2}{|c|}{ Ramachandran plot (Ramapage) } \\
\hline Favored & $93.9 \%$ \\
\hline Generously Allowed & $6.1 \%$ \\
\hline Disallowed & $0.0 \%$ \\
\hline
\end{tabular}

${ }^{a} \operatorname{Rsym}(\mathrm{I})=\Sigma|\mathrm{I}-<\mathrm{I}>| / \Sigma \mathrm{I} ;{ }^{b}$ Test set consists of $5 \%$ for all data. 


\subsection{Size Exclusion Chromatography and Anion Exchange}

Size exclusion chromatography (SEC) was performed using an $̈$ ATTA ${ }^{\mathrm{TM}}$ Explorer system (GE Healthcare Life Sciences) at room-temperature $\left(25^{\circ} \mathrm{C}\right)$, with a Superose 12 10/300 (GE) (GE Healthcare Life Sciences Pittsburgh, PA, USA) and BSA for calibration. Buffer containing $0.3 \mathrm{M} \mathrm{NaCl}, 50 \mathrm{mM}$ Tris $\mathrm{HCl}$ at $\mathrm{pH} 8.0$ and $0.02 \% \mathrm{NaN}_{3}$ was used to equilibrate the system and during the run.

\subsection{Analysis of Dissolved Crystals}

Crystals were transferred manually to a drop containing only the crystallization solution, in order to wash off any residual, un-crystallized protein present in the crystallization assay. Several crystals were transferred into the same drop where they were washed with the crystallization solutions several times. A final step of dissolving the crystals in a buffer containing $0.1 \mathrm{M} \mathrm{LiCl}$ and $10 \mathrm{mM} \mathrm{HEPES}$ at $\mathrm{pH}$ 7.8 resulted in the solution of dissolved crystals.

\subsection{Thermostability and Affinity Measurements}

Thermostability was determined using Differential Scanning Fluorimeter (DSF) using the NanoDSF Prometheus NT.48 (NanoTemper Technologies GmbH, München, Germany), with duplicates for each measurement. The affinity of intact and P61C hoefavidin towards 2-iminobiotin were measured by surface plasmon resonance (SPR) using a Biacore T200 optical biosensor instrument (Biacore AB, Uppsala, Sweden), both procedures previously detailed [26].

\subsection{TEM Analysis of P61C Hoefavidin}

Solution $(3 \mu \mathrm{L})$ of dissolved P61C crystals at a concentration of $0.5 \mathrm{mg} / \mathrm{ml}$ was applied to a glow discharged TEM grid (carbon supported film on 300 mesh Cu grids, Ted Pella, Ltd., Redding, CA, United States of America). After $30 \mathrm{~s}$ the excess liquid was blotted, the grids were washed on two droplets of de-ionized water, stained with $2 \%$ uranyl acetate for $30 \mathrm{~s}$ and allowed to dry in air. For the biotin complex TEM, dissolved crystals were incubated with biotin prior to applying them to the grid. The samples were examined using FEI Tecnai 12 G2 TWIN TEM operated at $120 \mathrm{kV}$. The images were recorded by a $4 \mathrm{~K} \times 4 \mathrm{~K}$ FEI Eagle CCD camera.

\section{Results}

\subsection{Generating the Covalently Linked Octamer}

The covalently linked P61C hoefavidin was designed based on the molecular packing of the intact hoefavidin crystal structure (PDB ID 4Z6J) [24]. The primary objective was to induce one mutation adding a Cys residue per each monomer in the position that will generate a disulfide bridge with its neighboring non-canonical monomer (which will also be mutated in the same position to a Cys residue). In this regard, the position of the mutation was selected based on the distances from symmetry related molecular partners. For this purpose, we chose to mutate Pro61 where its $C \alpha$ is $6.5 \AA$ away from the $\mathrm{C} \alpha$ of the relevant symmetry related Pro61 (Figure $3 \mathrm{~A}, \mathrm{~B}$ ), while disulfide bridges effective range is between 4.4 to $6.8 \AA$ of the $\mathrm{C} \alpha$ atoms [39]. The P61C mutant was consequently expressed and purified via a procedure similar to that of the wt hoefavidin [24]. 


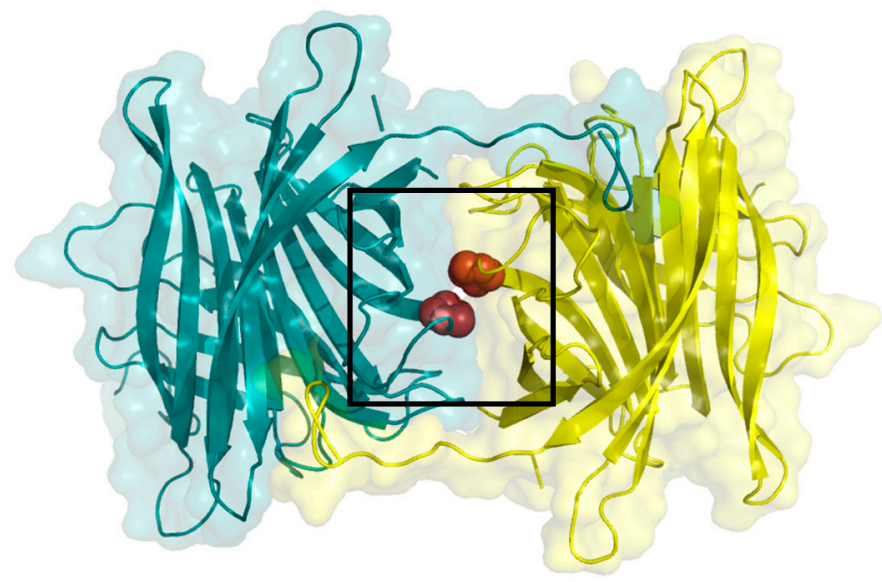

(A)

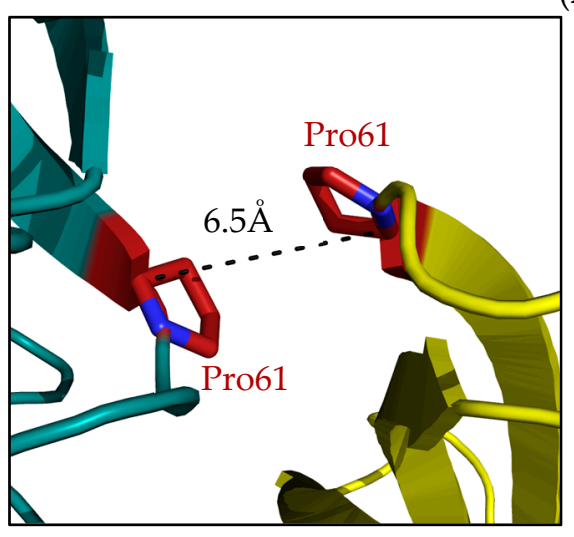

(B)

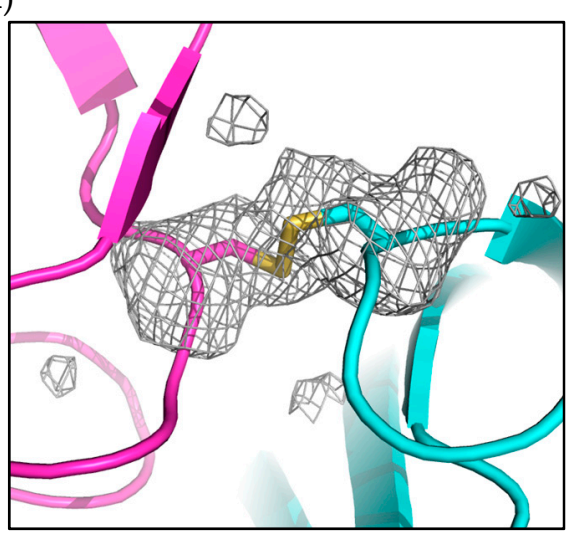

(C)

Figure 3. The P61C mutation site. (A) The interface between two non-canonical monomers where the mutation site was selected. (B) Enlargement of the region in the box showing the relative positions on Pro61 in the two monomers suitable for a mutation site based on C $\alpha$ distance. (C) The P61C mutation resulting in the formation of a disulfide bridge between the Cys61 residues, clearly indicated by the Fo-Fc unbiased omit map, removing residue Cys61. The map is calculated after several cycles of refinement and contoured at $2.5 \sigma$ cutoff at the resolution range of 43.5-2.0 $\AA$.

\subsection{Structure and Assembly of the P61C Hoefavidin}

The overall structure of the P61C hoefavidin maintains the topological characteristics of the intact hoefavidin, with the canonical 1-4 dimer in the asymmetric unit. The crystal structure reveals a covalently linked octamer, where the 4 disulfide bridges connect the 4 canonical dimers (Figure 3C). The disulfide bridges are mainly buried in the inner interface of the structure and are un-exposed to solvent and thus not effected by $\mathrm{pH}$ fluctuations (not shown). As demonstrated hereon the disulfide bridges are critical for the stabilization of the octameric assembly.

We have also assessed the nature of the overall assembly of wild-type and $\mathrm{P} 61 \mathrm{C}$ forms of hoefavidin using size exclusion chromatography (SEC) (Figure 4). In the wt form, SEC analysis revealed the presence of several forms of multimers yet upon the addition of biotin only a dimer was observed (Figure 4). With the P61C mutant multimers available in solution similarly to the wt hoefavidin. Yet upon addition biotin to the P61C hoefavidin, no change is observed with no overall dissociation into dimers. Hence, we can thus conclude that the P61C octamer is stable and does not dissociate in the presence of biotin. This verification is crucial, since the utilization of the system requires the stability of the octameric assembly upon the binding of biotin. 


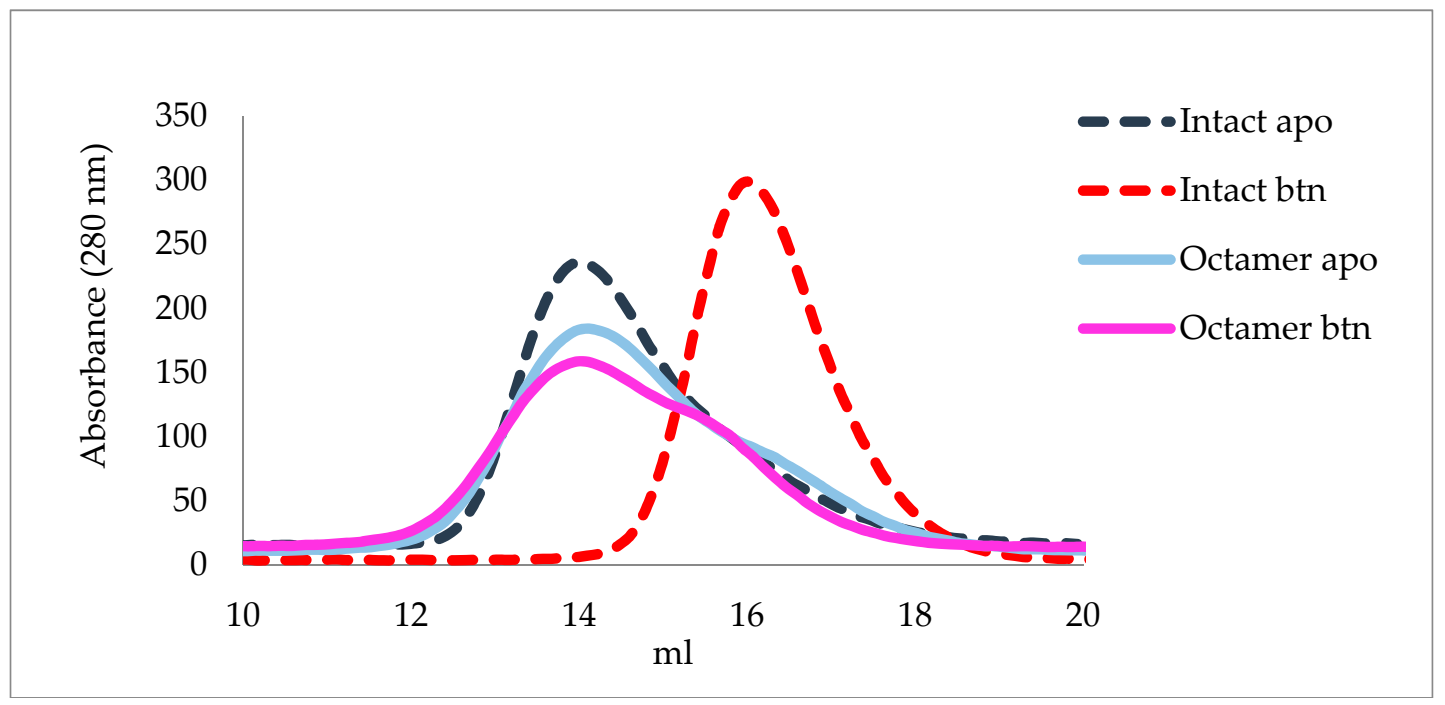

Figure 4. Size exclusion chromatography of wt and P61C hoefavidins in the apo and biotin complexed forms. The wt apo hoefavidin (dashed blue curve) displays a shift upon the biotin binding (dashed red curve) indicating dissociation of the octameric assembly solely into dimers. The P61C hoefavidin does not exhibit any major shift upon biotin binding, showing a similar profile for both forms (apo in cyan and biotin complex magenta). Additionally, the heterogeneity of the P61C peaks indicates that the P61C mutant is heterogeneous in solution.

\subsubsection{Obtaining a Homogeneous Octameric Sample}

After determining the stability of the P61C hoefavidin, we aimed to obtain a homogeneous sample containing solely the octameric form. SEC could not be used for specie separation as all forms are merged into one wide and extended peak (Figure 4) and Ion Exchange coupled to Multi Angle Light Scattering (IEX-MALS) was also attempted with limited success, due to a heterogeneous octameric fraction [40]. We thus resorted to a completely different approach using the crystals of the P61C hoefavidin as the source of purified octamers. For this purpose, crystals of the P61C hoefavidin were collected, thoroughly washed and dissolved, followed by incubation with fluorescent biotin. The consequent native gel clearly confirms the presence of a homogeneous octamer from the dissolved crystals (Figure 5A). For comparison, crystals of intact hoefavidin were also dissolved and incubated with biotin, yet they did not maintain their crystalline octameric characteristic but dissociated mainly into dimers (Figure 5B). 


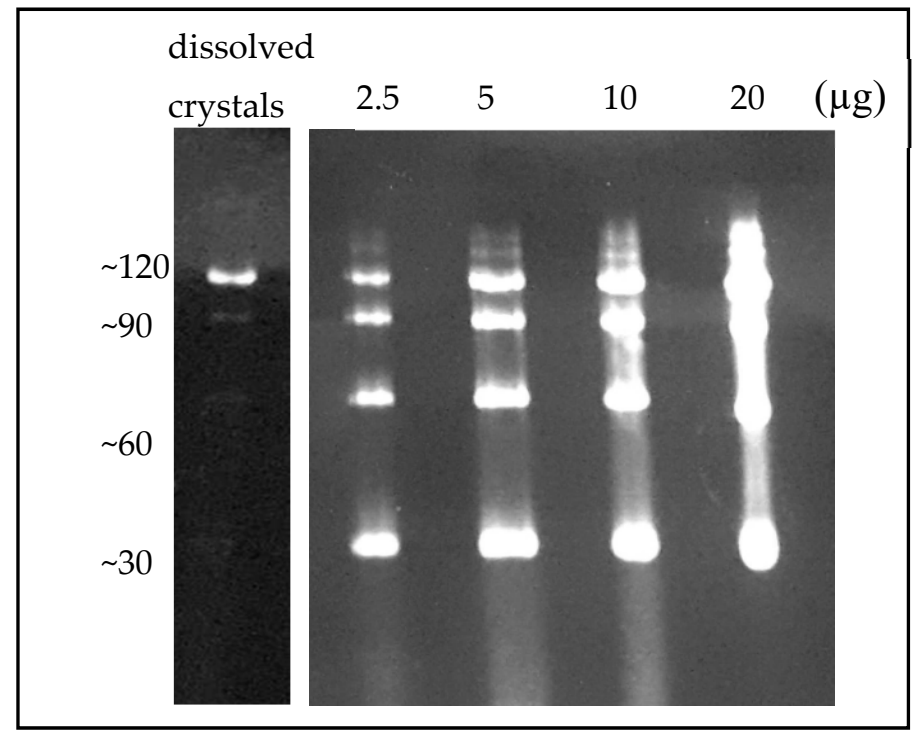

(A)

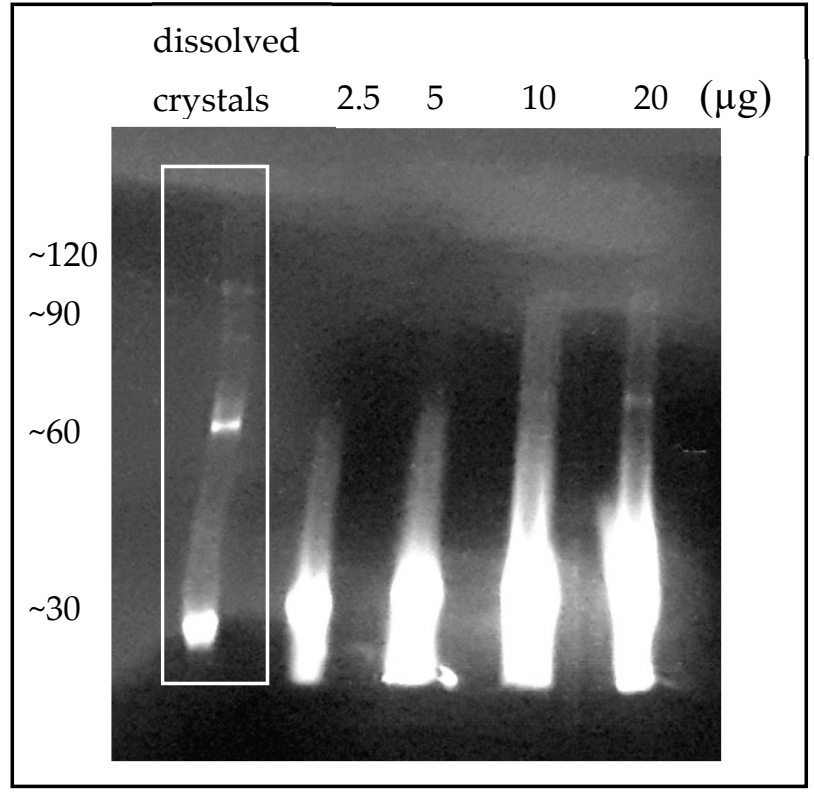

(B)

Figure 5. Native PAGE of wt and P61C hoefavidins complexed with biotin-4-fluorescein. (A) Upon crystallization and consequent dissolving of crystals (left panel) only the octamer is apparent. Purified P61C hoefavidin prior to crystallization (right panel) at different amounts ( $\mu \mathrm{g}$ ) of protein shows a heterogeneous profile of oligomers ranging from dimers to octamers. (B) Dissolved crystals of wt hoefavidin (left lane, indicated in a white rectangle) clearly show that although they are octamers in the crystalline state, they disintegrate into several types of oligomers upon binding of the fluorescent biotin. The other lanes show the pre-crystallized wt hoefavidin at different amounts $(\mu \mathrm{g})$.

\subsection{Thermostability Properties and Affinity Towards 2-Iminobiotin}

Once the purified protein was obtained, its affinity towards 2-iminobiotin was measured using Surface Plasmon Resonance (SPR) (Table 2 and Supplementary Materials Figure S1). The somewhat decreased affinity of 2-iminobiotin towards the octameric P61C hoefavidin in solution is probably the result of the presence on the C-terminal tail partially blocking the biotin binding site, without the possibility of dissociation into dimers as observed for the wt. Thermostability was measured using DSF, where an interesting result is notable for the apo forms (Table 2, and Supplementary Materials Figure S2). Apo P61C and wt hoefavidin samples display two peaks, indicating two points of change 
in the $350 \mathrm{~nm} / 330 \mathrm{~nm}$ ratio, while the P61C dissolved crystals show a single peak emphasizing sample homogeneity. In addition, as for all previously analyzed avidins the Tm values increase upon biotin binding inducing additional stability.

Table 2. Thermostability and affinity towards 2-iminobiotin.

\begin{tabular}{cccc}
\hline Protein & Tm apo $\left({ }^{\circ} \mathrm{C}\right)$ & $\operatorname{Tm}$ Biotin Complex $\left({ }^{\circ} \mathrm{C}\right)$ & $\begin{array}{c}\text { Affinity towards 2-Iminobiotin } \\
\left({ }^{*} \mathbf{1 0} \mathbf{0}^{-7} \mathbf{M}\right)\end{array}$ \\
\hline P61C hoefavidin & $\begin{array}{l}69.1 \pm 0.06, \\
80.9 \pm 0.05\end{array}$ & $88.8 \pm 0.78$ & $22 \pm 5.9$ \\
\hline $\begin{array}{c}\text { P61C hoefavidin } \\
\text { dissolved crystals }\end{array}$ & $81.5 \pm 0.08$ & $89.5 \pm 0.10$ & - \\
\hline WT Intact hoefavidin & $73.0 \pm 0.16$, & $>95$ & $2.0[24]$ \\
\hline
\end{tabular}

\subsection{TEM Analysis of P61C Hoefavidin}

The P61C assembly derived from dissolved crystals was further analyzed using Transmission Electron Microscope (TEM) (Figure 6). In the absence and presence of biotin there was no change in observed pattern where both the apo and the biotin complexed forms displayed many flower-shaped spheres with an approximate diameter of $7 \AA$, clearly indicating the P61C cylindrical octameric assembly and emphasizing its stability.

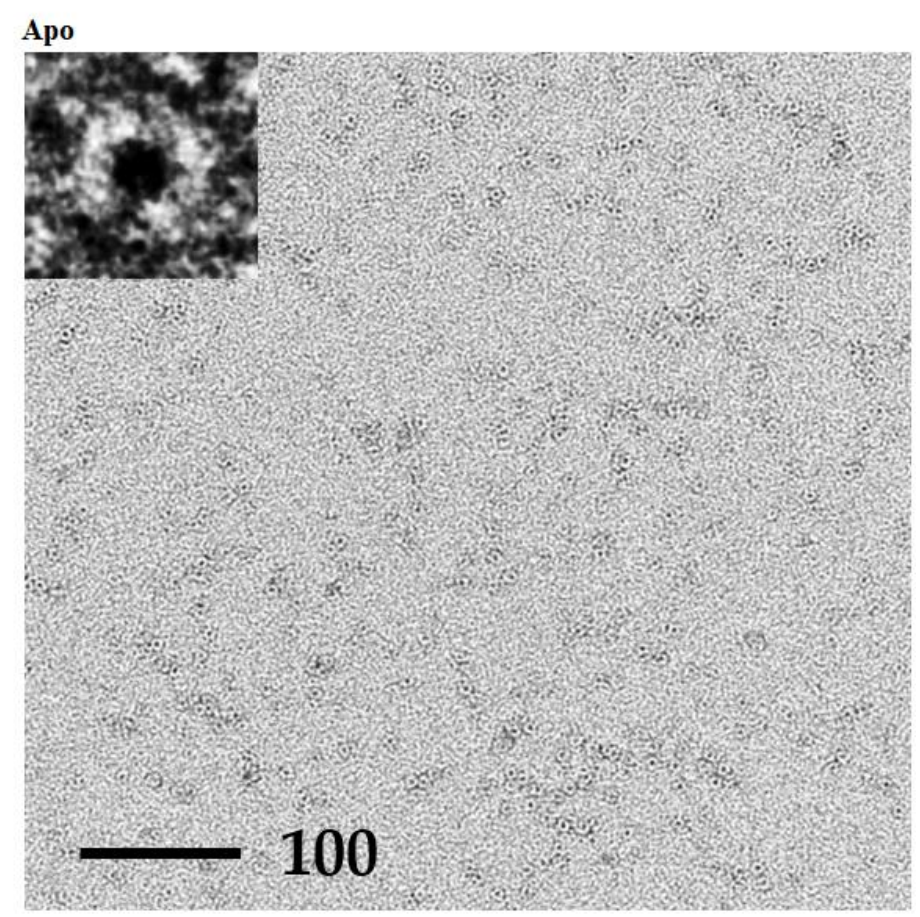

Figure 6. Cont. 


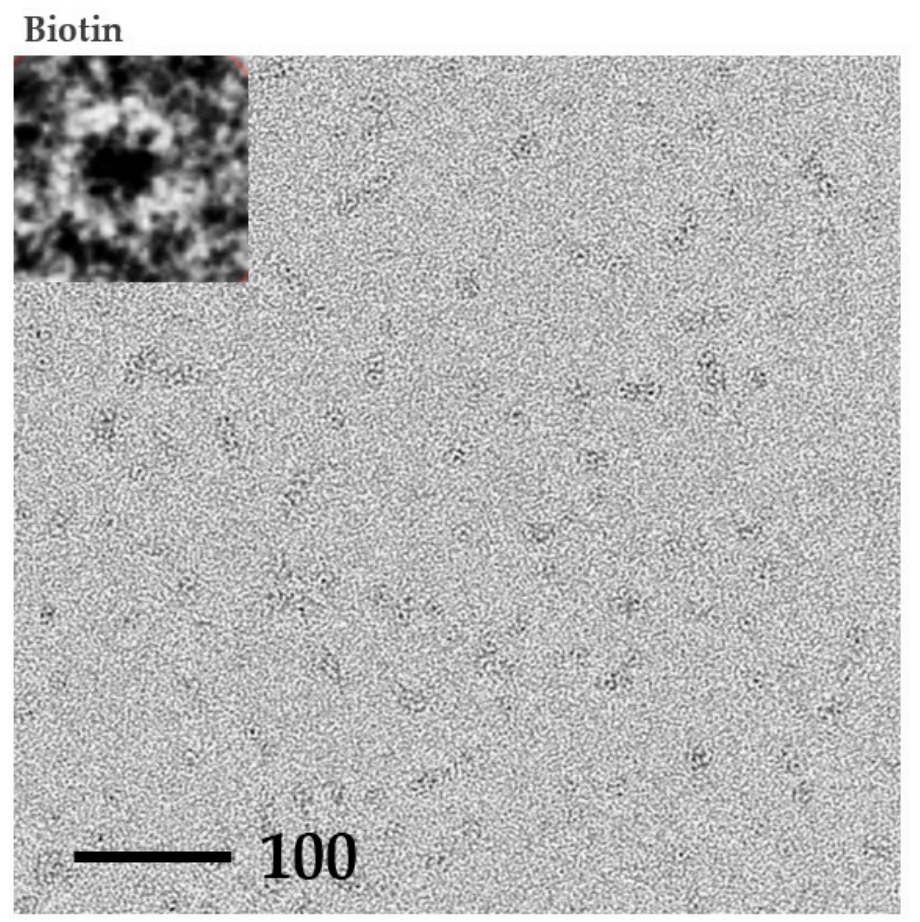

Figure 6. TEM images of dissolved P61C hoefavidin crystals. TEM images of negatively stained P61C hoefavidin dissolved crystals in an apo or biotin complex form, as indicated. Insets show one typical enlarged particle of each sample demonstrating the cylindrical assembly. Many particles could be detected in each sample, having the size and shape of the expected octamer. There is no apparent difference between the apo and biotin complex samples, indicating the stability of the octamer.

\section{Discussion}

The exploitation and wide use of the avidin-biotin system made way for many variations and manipulations diversifying and increasing the possible applications. In this study, we present a novel tool, a stable hoefavidin octamer by mutagenesis and a subsequent covalent link. For the tetrameric avidins the vast array of utilizations is regularly used without a decline in the number of applications. These have reached an optimum where the need for the system diversification is desired. Thus, higher valency high-affinity biotin binders should not be overlooked since they could extend the toolbox of usage of this unique protein-biotin system. In this regard, the availability of the stabilized P61C octameric hoefavidin provides a template for molecular manipulations and nano-technological applications. Many studies employ the avidin-biotin system as specific molecular glue and would benefit from the added binding sites and consequent binding capacity. A relevant system became recently apparent where avidin was used in bone-tissue engineering studies [41].

The process efficiency and cost-benefit specifications are explicitly addressed and an octameric biotin binder might prove a useful tool to such applications.

All dimeric avidins published to date demonstrate a higher oligomeric assembly in the crystalline states than initially analyzed in solution. Interfaces conserved between similar proteins are often indicative of biological relevance [42], thus the reoccurrence of this phenomenon led to re-examination of the solution state of hoefavidin and facilitated the construction of the covalently stabilized hoefavidin octamer. The dissolved crystals of P61C hoefavidin display the octameric cylindrical structure via transmission electron microscope (TEM). These findings compliment the assembly observed in the crystal and substantiate its validity. Combining various methods that cross-validate the results provides a complete image regarding the properties of P61C hoefavidin.

In synthetic chemistry, purification via crystallization has been a common practice for many years, where the product molecule is selected out from the rest of the available side products or adducted. 
In the case of hoefavidin and other dimeric avidins, the proteins are essentially pure and tend to crystallize quite readily, but in most cases lack oligomeric homogeneity. Crystallization of hoefavidin is the driving force of segregating these particles or shifting the equilibrium resulting in a homogeneous setting of octamers. For the P61C hoefavidin, once the octamers are formed, they do not dissociate in solution even upon biotin binding. Conversely, when dissolving the crystals of the wt protein we have observed a heterogeneous sample consisting mainly of dimers (Figure 5). The structure-based design of the P61C mutant promoted the formation of a stabilizing covalent link that verified the homogeneity in the crystalline state of the octamer. This method extends a newly introduced concept in protein purification and macromolecular crystallography, where the crystal is used for selection of the preferred oligomeric species, and the sample for crystallization is not completely homogeneous prior to setting up the crystallization experiment [43,44]. The P61C hoefavidin purification protocol, which includes dissolving crystals in order to obtain a homogeneous sample, presents a unique aspect regarding the role of crystallization in the production process. The crystals are not only a way to determine the three-dimensional structure, they are pivotal in obtaining a homogeneous octameric sample.

Supplementary Materials: The following are available online at http://www.mdpi.com/2073-4352/9/7/353/s1, Figure S1: SPR sensorgram, Figure S2: DSF traces of P61C hoefavidin before and after crystallization and of wt hoefavidin.

Author Contributions: O.L. and O.A. planned and preformed the experiments, analyzed the data and wrote the manuscript. Y.L.K. preformed the EM analysis.

Funding: This research was partially supported by the Minerva Center for Bio-hybrid Complex Systems.

Acknowledgments: We would like to thank the staff of ESRF, Grenoble, France for their outstanding help, and maintaining and upgrading the facility.

Conflicts of Interest: The authors declare no conflict of interest.

\section{References}

1. Lesch, H.P.; Kaikkonen, M.U.; Pikkarainen, J.T.; Yla-Herttuala, S. Avidin-biotin technology in targeted therapy. Expert Opin. Drug Deliv. 2010, 7, 551-564. [CrossRef] [PubMed]

2. Laitinen, O.H.; Nordlund, H.R.; Hytonen, V.P.; Kulomaa, M.S. Brave new (strept)avidins in biotechnology. Trends Biotechnol. 2007, 25, 269-277. [CrossRef] [PubMed]

3. Yeates, T.O. Geometric Principles for Designing Highly Symmetric Self-Assembling Protein Nanomaterials. Annu. Rev. Biophys. 2017, 46, 23-42. [CrossRef] [PubMed]

4. Green, N.M. Avidin. Adv. Protein Chem. 1975, 29, 85-133. [PubMed]

5. Green, N.M. Avidin and streptavidin. Methods Enzymol. 1990, 184, 51-67.

6. Chaiet, L.; Wolf, F.J. The Properties of Streptavidin, a Biotin-Binding Protein Produced by Streptomycetes. Arch. Biochem. Biophys. 1964, 106, 1-5. [CrossRef]

7. Takakura, Y.; Tsunashima, M.; Suzuki, J.; Usami, S.; Kakuta, Y.; Okino, N.; Ito, M.; Yamamoto, T. Tamavidins-Novel avidin-like biotin-binding proteins from the Tamogitake mushroom. FEBS J. 2009, 276, 1383-1397. [CrossRef]

8. Maatta, J.A.; Helppolainen, S.H.; Hytonen, V.P.; Johnson, M.S.; Kulomaa, M.S.; Airenne, T.T.; Nordlund, H.R. Structural and functional characteristics of xenavidin, the first frog avidin from Xenopus tropicalis. BMC Struct. Biol. 2009, 9, 63. [CrossRef]

9. Taskinen, B.; Zmurko, J.; Ojanen, M.; Kukkurainen, S.; Parthiban, M.; Maatta, J.A.; Leppiniemi, J.; Janis, J.; Parikka, M.; Turpeinen, H.; et al. Zebavidin—An avidin-like protein from zebrafish. PLoS ONE 2013, 8, e77207. [CrossRef]

10. Ahlroth, M.K.; Kola, E.H.; Ewald, D.; Masabanda, J.; Sazanov, A.; Fries, R.; Kulomaa, M.S. Characterization and chromosomal localization of the chicken avidin gene family. Anim. Genet. 2000, 31, 367-375. [CrossRef]

11. Laitinen, O.H.; Hytonen, V.P.; Ahlroth, M.K.; Pentikainen, O.T.; Gallagher, C.; Nordlund, H.R.; Ovod, V.; Marttila, A.T.; Porkka, E.; Heino, S.; et al. Chicken avidin-related proteins show altered biotin-binding and physico-chemical properties as compared with avidin. Biochem. J. 2002, 363, 609-617. [CrossRef] [PubMed] 
12. Sardo, A.; Wohlschlager, T.; Lo, C.; Zoller, H.; Ward, T.R.; Creus, M. Burkavidin: A novel secreted biotin-binding protein from the human pathogen Burkholderia pseudomallei. Protein Expr. Purif. 2011, 77, 131-139. [CrossRef] [PubMed]

13. Green, N.M.; Joynson, M.A. A preliminary crystallographic investigation of avidin. Biochem. J. 1970, 118, 71-72. [CrossRef] [PubMed]

14. Hendrickson, W.A.; Pahler, A.; Smith, J.L.; Satow, Y.; Merritt, E.A.; Phizackerley, R.P. Crystal structure of core streptavidin determined from multiwavelength anomalous diffraction of synchrotron radiation. Proc. Natl. Acad. Sci. USA 1989, 86, 2190-2194. [CrossRef] [PubMed]

15. Livnah, O.; Bayer, E.A.; Wilchek, M.; Sussman, J.L. Three-dimensional structures of avidin and the avidin-biotin complex. Proc. Natl. Acad. Sci. USA 1993, 90, 5076-5080. [CrossRef] [PubMed]

16. Meir, A.; Helppolainen, S.H.; Podoly, E.; Nordlund, H.R.; Hytonen, V.P.; Maatta, J.A.; Wilchek, M.; Bayer, E.A.; Kulomaa, M.S.; Livnah, O. Crystal structure of rhizavidin: Insights into the enigmatic high-affinity interaction of an innate biotin-binding protein dimer. J. Mol. Biol. 2009, 386, 379-390. [CrossRef] [PubMed]

17. Laitinen, O.H.; Hytonen, V.P.; Nordlund, H.R.; Kulomaa, M.S. Genetically engineered avidins and streptavidins. Cell. Mol. Life Sci. 2006, 63, 2992-3017. [CrossRef] [PubMed]

18. Howarth, M.; Chinnapen, D.J.; Gerrow, K.; Dorrestein, P.C.; Grandy, M.R.; Kelleher, N.L.; El-Husseini, A.; Ting, A.Y. A monovalent streptavidin with a single femtomolar biotin binding site. Nat. Methods 2006, 3, 267-273. [CrossRef] [PubMed]

19. Hytonen, V.P.; Nordlund, H.R.; Horha, J.; Nyholm, T.K.; Hyre, D.E.; Kulomaa, T.; Porkka, E.J.; Marttila, A.T.; Stayton, P.S.; Laitinen, O.H.; et al. Dual-affinity avidin molecules. Proteins 2005, 61, 597-607. [CrossRef]

20. Nordlund, H.R.; Hytonen, V.P.; Horha, J.; Maatta, J.A.; White, D.J.; Halling, K.; Porkka, E.J.; Slotte, J.P.; Laitinen, O.H.; Kulomaa, M.S. Tetravalent single-chain avidin: From subunits to protein domains via circularly permuted avidins. Biochem. J. 2005, 392, 485-491. [CrossRef]

21. Lim, K.H.; Huang, H.; Pralle, A.; Park, S. Stable, high-affinity streptavidin monomer for protein labeling and monovalent biotin detection. Biotechnol. Bioeng. 2013, 110, 57-67. [CrossRef] [PubMed]

22. Demonte, D.; Drake, E.J.; Lim, K.H.; Gulick, A.M.; Park, S. Structure-based engineering of streptavidin monomer with a reduced biotin dissociation rate. Proteins 2013, 81, 1621-1633. [CrossRef] [PubMed]

23. Goodsell, D.S.; Olson, A.J. Structural symmetry and protein function. Annu. Rev. Biophys. Biomol. Struct. 2000, 29, 105-153. [CrossRef] [PubMed]

24. Avraham, O.; Meir, A.; Fish, A.; Bayer, E.A.; Livnah, O. Hoefavidin: A dimeric bacterial avidin with a C-terminal binding tail. J. Struct. Biol. 2015, 191, 139-148. [CrossRef] [PubMed]

25. Meir, A.; Bayer, E.A.; Livnah, O. Structural adaptation of a thermostable biotin-binding protein in a psychrophilic environment. J. Biol. Chem. 2012, 287, 17951-17962. [CrossRef] [PubMed]

26. Avraham, O.; Bayer, E.A.; Livnah, O. Crystal structure of afifavidin reveals common features of molecular assemblage in the bacterial dimeric avidins. FEBS J. 2018, 285, 4617-4630. [CrossRef] [PubMed]

27. Helppolainen, S.H.; Nurminen, K.P.; Maatta, J.A.; Halling, K.K.; Slotte, J.P.; Huhtala, T.; Liimatainen, T.; Yla-Herttuala, S.; Airenne, K.J.; Narvanen, A.; et al. Rhizavidin from Rhizobium etli: The first natural dimer in the avidin protein family. Biochem. J. 2007, 405, 397-405. [CrossRef]

28. Meir, A.; Livnah, O. Challenging semi-bootstrapping molecular-replacement strategy reveals intriguing crystal packing of rhizavidin. Acta Cryst. Sect. F Struct. Biol. Cryst. Commun. 2010, F66, 373-378. [CrossRef]

29. Humbert, N.; Zocchi, A.; Ward, T.R. Electrophoretic behavior of streptavidin complexed to a biotinylated probe: A functional screening assay for biotin-binding proteins. Electrophoresis 2005, 26, 47-52. [CrossRef]

30. Kada, G.; Falk, H.; Gruber, H.J. Accurate measurement of avidin and streptavidin in crude biofluids with a new, optimized biotin-fluorescein conjugate. Biochim. Biophys. Acta 1999, 1427, 33-43. [CrossRef]

31. Hofmann, K.; Wood, S.W.; Brinton, C.C.; Montibeller, J.A.; Finn, F.M. Iminobiotin affinity columns and their application to retrieval of streptavidin. Proc. Natl. Acad. Sci. USA 1980, 77, 4666-4668. [CrossRef] [PubMed]

32. Bergfors, T. Seeds to crystals. J. Struct. Biol. 2003, 142, 66-76. [CrossRef]

33. Stura, E.A.; Wilson, I.A. Applications of the Streak Seeding Technique in Protein Crystallization. J. Cryst. Growth 1991, 110, 270-282. [CrossRef]

34. Incardona, M.F.; Bourenkov, G.P.; Levik, K.; Pieritz, R.A.; Popov, A.N.; Svensson, O. EDNA: A framework for plugin-based applications applied to X-ray experiment online data analysis. J. Synchrotron Radiat. 2009, 16, 872-879. [CrossRef] [PubMed] 
35. Vagin, A.; Teplyakov, A. Molecular replacement with MOLREP. Acta Cryst. Sect. D Biol. Cryst. 2010, 66, 22-25. [CrossRef] [PubMed]

36. Winn, M.D.; Ballard, C.C.; Cowtan, K.D.; Dodson, E.J.; Emsley, P.; Evans, P.R.; Keegan, R.M.; Krissinel, E.B.; Leslie, A.G.; McCoy, A.; et al. Overview of the CCP4 suite and current developments. Acta Cryst. Sect. D Biol. Cryst. 2011, 67, 235-242. [CrossRef] [PubMed]

37. Vagin, A.A.; Steiner, R.A.; Lebedev, A.A.; Potterton, L.; McNicholas, S.; Long, F.; Murshudov, G.N. REFMAC5 dictionary: Organization of prior chemical knowledge and guidelines for its use. Acta Cryst. Sect. D Biol. Cryst. 2004, 60, 2184-2195. [CrossRef] [PubMed]

38. Emsley, P.; Lohkamp, B.; Scott, W.G.; Cowtan, K. Features and development of Coot. Acta Cryst. Sect. D Biol. Cryst. 2010, 66, 486-501. [CrossRef] [PubMed]

39. Richardson, J.S. The anatomy and taxonomy of protein structure. Adv. Protein Chem. 1981, 34, 167-339.

40. Amartely, H.; Avraham, O.; Friedler, A.; Livnah, O.; Lebendiker, M. Coupling Multi Angle Light Scattering to Ion Exchange chromatography (IEX-MALS) for protein characterization. Sci. Rep. 2018, 8, 6907. [CrossRef] [PubMed]

41. Cheng, C.H.; Lai, Y.H.; Chen, Y.W.; Yao, C.H.; Chen, K.Y. Immobilization of bone morphogenetic protein-2 to gelatin/avidin-modified hydroxyapatite composite scaffolds for bone regeneration. J. Biomater. Appl. 2019, 33, 1147-1156. [CrossRef] [PubMed]

42. Xu, Q.; Dunbrack, R.L.J. Principles and characteristics of biological assemblies in experimentally determined protein structures. Curr. Opin. Struct. Biol. 2019, 55, 34-49. [CrossRef] [PubMed]

43. Giffard, M.; Ferte, N.; Ragot, F.; El Hajji, M.; Castro, B.; Bonnete, F. Urate oxidase purification by salting-in crystallization: Towards an alternative to chromatography. PLoS ONE 2011, 6, e19013. [CrossRef] [PubMed]

44. Hekmat, D. Large-scale crystallization of proteins for purification and formulation. Bioprocess Biosyst. Eng. 2015, 38, 1209-1231. [CrossRef] [PubMed]

(C) 2019 by the authors. Licensee MDPI, Basel, Switzerland. This article is an open access article distributed under the terms and conditions of the Creative Commons Attribution (CC BY) license (http://creativecommons.org/licenses/by/4.0/). 